\title{
Evaluation of the Effect of Daptomycin, a Glycopeptide Agent, on Intact Intervertebral Disc Tissue
}

\author{
Necati KAPLAN ${ }^{1}$, Ibrahim YILMAZ², Numan KARAARSLAN³ , Duygu YASAR SIRIN", Abdullah Talha SIMSEK ${ }^{3}$, \\ Tezcan CALISKAN ${ }^{3}$, Rifat BIRCAN ${ }^{4}$, Hanefi OZBEK ${ }^{2}$ \\ ${ }^{1}$ Istanbul Rumeli University, Corlu Reyap Hospital, Department of Neurosurgery, Tekirdag, Turkey \\ 2Istanbul Medipol University School of Medicine, Department of Medical Pharmacology, Istanbul, Turkey \\ ${ }^{3}$ Namik Kemal University School of Medicine, Department of Neurosurgery, Tekirdag, Turkey \\ ${ }^{4}$ Namik Kemal University, Faculty of Arts and Sciences, Department of Molecular Biology and Genetics, Tekirdag, Turkey
}

Corresponding author: Numan KARAARSLAN numikara@yahoo.com

\section{ABSTRACT}

AIM: To evaluate the effects of pre- and intra-operatively administered daptomycin (DAP) on the intact human primary intervertebral disc tissue cells.

MATERIAL and METHODS: Primary cell cultures were established using tissues obtained through decompressive laminectomy, traumatic intervertebral disc herniation excision, and posterior transpedicular stabilization. Non-drug-administered samples were used as a control group. The samples treated with DAP formed the study group. Molecular assays for proliferation and gene expression were performed. The obtained data were evaluated statistically, and results with a value of $p<0.05$ were accepted as significant.

RESULTS: While no reduction was observed in the proliferation, the gene expression of intact intervertebral disc tissue cells was time-dependently decreased compared to the control group, and these results were reported to be statistically significant.

CONCLUSION: This study observed the effect that a pharmaceutical preparation, which was used on intervertebral disc tissue before and after the operation, had on normal, healthy, and intact tissue. It concludes that alterations in the expression of genes involved in the anabolic and/or catabolic process, even in adjacent healthy tissue, may slow down the healing process of the damaged tissue or cause undesired cell differentiation.

KEYWORDS: Intervertebral disc, CHAD, COMP, Daptomycin, IL-1ß, MMPs

\section{INTRODUCTION}

$\mathrm{D}$ aptomycin (DAP) is a novel lipopeptide antibiotic with strong bactericidal activity against methicillin-resistant Staphylococcus aureus (MRSA) $(25,30,47)$. Following the approval of usage issued by the United States Food and Drug Administration in appropriate cases (2), studies on DAP have gained popularity, and studies on this matter have increased $(4,7,8,29,32,36,38,40)$.

In a review concerning the pharmacokinetics and pharmacodynamics of active antibiotics, the resistance mechanisms developed against these agents and in-vitro combinations of these agents were investigated (36). In this study, clinical trials focusing on the urinary tract, intra-abdominal, central nervous system, and bloodstream system infections due to Enterococci were evaluated (36). It has been underlined that DAP demonstrates clinical efficacy against vancomycin (VCM) resistant Enterococci (VRE) (36). Cases in the literature demonstrated that interverbal disc infections caused by MRSA (discitis) were successfully treated with intravenous DAP $(7,38)$.

\footnotetext{
Necati KAPLAN D : 0000-0001-5672-0566

Ibrahim YILMAZ (D) : 0000-0002-5136-8791

Numan KARAARSLAN (D) : 0000-0001-5590-0637

Duygu YASAR SIRIN D : 0000-0002-1224-442X

Abdullah Talha SIMSEK (D) : 0000-0002-8668-3935

Tezcan CALISKAN

Rifat BIRCAN (1) : 0000-0002-5894-5918 Hanefi OZBEK (D) : 0000-0002-8084-7855
} 
Due to antibiotic resistance stemming from the failure to comply with rational antibiotic use procedures, the search for local rather than systemic DAP applications has become popular, as this avoids these types of adverse effects, particularly in the fields of neurosurgery and orthopedic surgery (25).

In addition to discitis, a study indicated the successful use of DAP for the treatment of ventriculostomy-associated meningitis caused by multidrug-resistant coagulase-negative Staphylococcus epidermidis (8). It has also been suggested that, in addition to surgical procedures, local antibiotic administration to the intraoperative surgical site may play a significant role in the efficacy of treatment to prevent osteomyelitis after trauma $(4,25)$.

There are also reports in the literature that suggest treatment using local rather than systemic application yields more effective results against infections that form a biofilm layer (40). However, studies reporting that the pre-and/or intraoperative irrigation of instruments with antibiotics may not be effective in preventing infection are also found in the literature (22).

A review of publications on the side effects and/or adverse events of DAP shows that cases of severe myopathy and acute renal failure have been reported $(26,35)$. In a report describing a single case (38), it was reported that DAP may be safely used in MRSA discitis. However, in a report describing two cases a year later, the opposite opinion was reported (3).

In a study with high-evidential value in which the effects of DAP were investigated on primary human chondrocyte cultures compared to those of the VCM at the molecular level, it was emphasized that changes in cell morphology and deaths were observed in the DAP-administered culture samples after administration (25). In addition, observing the cessation of proliferation and cell death, it was underlined that gene expression in the chondroadherin (CHAD) genewhich is a nucleus pulposus (NP) specific marker protein and responsible for the development of the dorsal column with the spinal cord-and the expression levels of the hypoxia-induced transcription factor-1 alpha and type II collagen decreased (25).

Both positive $(7,25,29,38)$, and negative $(3,22,25,26,34)$ effects are referred by studies in the literature regarding DAP. However, there are no pharmaco-molecular studies of highevidential value that evaluate the efficacy of DAP on healthy and intact intervertebral disc tissue cells in the literature.

In this context, this study is the first in the literature that aims to evaluate the effect of DAP on the proliferation in the primary cell cultures isolated from intact human intervertebral disc tissue. In addition, the surface morphologies of the samples were assessed microscopically in DAP-administered culture samples. Subsequently, the gene expression levels of CHAD (25), cartilage oligomeric matrix protein (COMP) (37), interleukin-1 beta (IL-1ß) (37), and matrix metalloproteinase (MMP)-7 and MMP-19 (37) were evaluated with real-time polymerase chain reaction (RT-PCR). One of the main extracellular matrix (ECM) components of a healthy intervertebral disc CHAD binds to integrin and collagen; it regulates cell metabolism and ECM structure with a promoting role in matrix homeostasis $(16,37)$. COMP preserves the structural integrity of the ECM; it binds other matrix proteins and catalyzes the polymerization of type II collagen fibrils and also prevents cartilage from vascularization. If the tissue undergoes degeneration as a result of ECM degradation, low molecular weight degradation products form. These products can induce inflammation, promoting macrophage mediated production of IL-1b in vivo $(16,37)$.

Since the disc is primarily avascular and annulus fibrosus (AF)/ NP cells themselves can produce proinflammatory cytokines, we assessed whether there was a change in IL-1 $\beta$ expression in our in vitro study. Increased IL-1 $\beta$ in a degenerating disc initiates signaling pathways that can increase MMP expression causing a cycle of matrix destruction $(16,37)$. In this context, the participation of changes in the gene expression of aggrecan and collagen type II degrading enzyme MMP-7 in ECM degradation, and the association of MMP-19 with the destruction of COMP were evaluated (37). These evaluated genetic markers were also chosen because they may elucidate the post-operative tissue healing process.

\section{MATERIAL and METHODS}

The research was conducted with the approval of the Local Ethics Committee of Istanbul, Medipol University School of Medicine (29.11.2017-10840098/604.01.01/E.44192). Written informed consent was obtained from all patients prior to inclusion. Analyses were performed by the same researchers and were repeated at least three times to minimize experimental errors.

\section{Surgical Resection of the Tissueand Selection Criteria of the Cases Whose Tissue was Used}

It is known that HMG-CoA reductase inhibitors, such as statins, are incompatible with DAP (35). Therefore, one of the tissues initially obtained from seven patients was not included in the study, as one patient used statin group medication.

The age range of the six patients whose intervertebral disc tissues were resected varied from 28 to 42 years, and the mean age was $33.83 \pm 4.84$ years. After the evaluation of the preoperative lumbar magnetic resonance imaging, patients with spinal cord compression due to traumatic disc herniation and with a vertebral fracture in the thoracolumbar region were selected for surgical intervention. Resection of the intact disc tissues was performed through decompressive laminectomy, traumatic intervertebral disc herniation excision, and posterior transpedicular stabilization $(1,19,21,23,24)$.

\section{Preparation of Primary Cell Cultures and DAP Addition to the Prepared Culture Samples}

Cultures were maintained by replacing the medium every two days. DAP was added to perform experiments on the cell cultures that became confluent and adhered to the floor at the end of the overnight incubation period $(18,20-22,24)$, and 350 $\mathrm{mg}$ of DAP (Cubicin $350 \mathrm{mg}$ ) was dissolved in $7 \mathrm{ml}$ of $0.9 \%$ $\mathrm{NaCl}$. Thus, a stock solution with a concentration of $50 \mathrm{mg} /$ mI DAP was prepared. To determine the doses to be applied 
to cultures, the safe dose range of DAP indicated in studies with high-evidential value were taken into account $(6,13)$. The main stock solution containing $1.28 \mu \mathrm{l}$ of DAP was added to each $\mathrm{ml}$ of the medium to reach a final concentration of $64 \mu \mathrm{g} /$ $\mathrm{ml}$. DAP was not added to the cultures of the control group. The analyses of both the DAP-administered cultures and nonDAP-administered cultures were performed at $0,24,48$, and 72 hours.

\section{Analyses Applied to the Cell Culture Samples}

Evaluations of the analyses conducted at 24,48 , and $72 \mathrm{~h}$ were performed at a magnification of $\times 4, \times 10, \times 20$, and $\times 40$ [inverted light microscope (Olympus CKX41)]. In addition, the samples were examined using a fluorescence microscope (Leica DM 2500) at the same magnifications. Microphotographs were recorded using Cytovision Capture Station imaging software.

Membrane permeability tests were performed with acridine orange $(\mathrm{AO})$ andpropidium iodide $(\mathrm{PI})$ staining, which is a non-vital dye. After staining, the live cells generate green fluorescence, and the dead cells generate red fluorescence. During these evaluations, the protocols of Karaarslan et al. were used $(1,19-21,23,24,42,43)$.

Fixation of the cells in the control and study group samples prepared separately for Giemsa (Cat\# GS500, Sigma, USA) staining was provided with a mixture of $8 \%$ glutaraldehyde and $25 \%$ cacodylate buffer. After Giemsa stain was added to the fixated culture samples, microscopic evaluations were again performed with an inverted light microscope.

The cytotoxicity and cytostatic activity of proliferating cells were measured using the MTT commercial kit (Vybrant MTT Cell Proliferation Assay, Cat\#V13154, Thermo Fisher Scientific, USA), which is based on the principle that for mazan crystals generate thiazole blue coloration. The viability of the cells in the control group samples to which DAP was not initially added was considered to be $100 \%$ in MTT assays performed at $570 \mathrm{~nm}$ absorbance. The proliferation and inhibition of the proliferation were calculated using the following formulas, respectively: Test OD/Control ODX100 and 1-Test OD/Control $O D$; data were then recorded for statistical analysis $(1,19-$ 21,23,24,42,43).

Total ribonucleic acid (RNA) was extracted from cultured primary human AF/NP cells using the PureLink RNA mini kit (Cat\# 12183020, ThermoFisher Scientific, USA). RNA quantity in each sample was measured using an ultraviolet spectrophotometer. All genes were amplified using TaqMan ${ }^{\circledR}$ Gene Expression assays for CHAD, ACT $\beta$, COMP, MMP-7, MMP-19, and IL-1 $\beta$. Quantitative RT-PCR was performed on an Applied Biosystems 7300/7500 RT-PCR system (Thermo Fisher Scientific, Inc.) $(1,19,21,23,24,42)$.

The statistical analyses were performed using Minitab software (version 18.0), and the data were evaluated at $95 \%$ confidence interval. Descriptive statistics were presented as a mean \pm standard deviation (SD). Analysis of variance (ANOVA) was used to determine how many independent variables interacted with each other and the effects of these interactions on the dependent variable. When differences across groups were observed, Tukey's honestly significant difference (HSD) post-hoc test was used for multiple pairwise comparisons. The alpha significance value was accepted as $p<0.05$.

\section{RESULTS}

When the results of MTT analysis were evaluated, it was found that the number of viable cells in the control group cultures decreased between cultures at 0 hour and 24 hours, while the number in the experimental group to which DAP was applied increased $(p<0.05)$ (Figure 1$)$. In microscopic examinations, it was observed that cells in both the control and administered cultures maintained their specific morphology (Figure 2A$U)$. When gene expressions were evaluated in cultures at 24 hours, the CHAD gene expression was slightly reduced in both the control and DAP groups relative to the 0 hour cultures, with relative quantification $\left(R Q=2-\Delta \Delta^{\mathrm{Ct}}\right)=0.7$ and

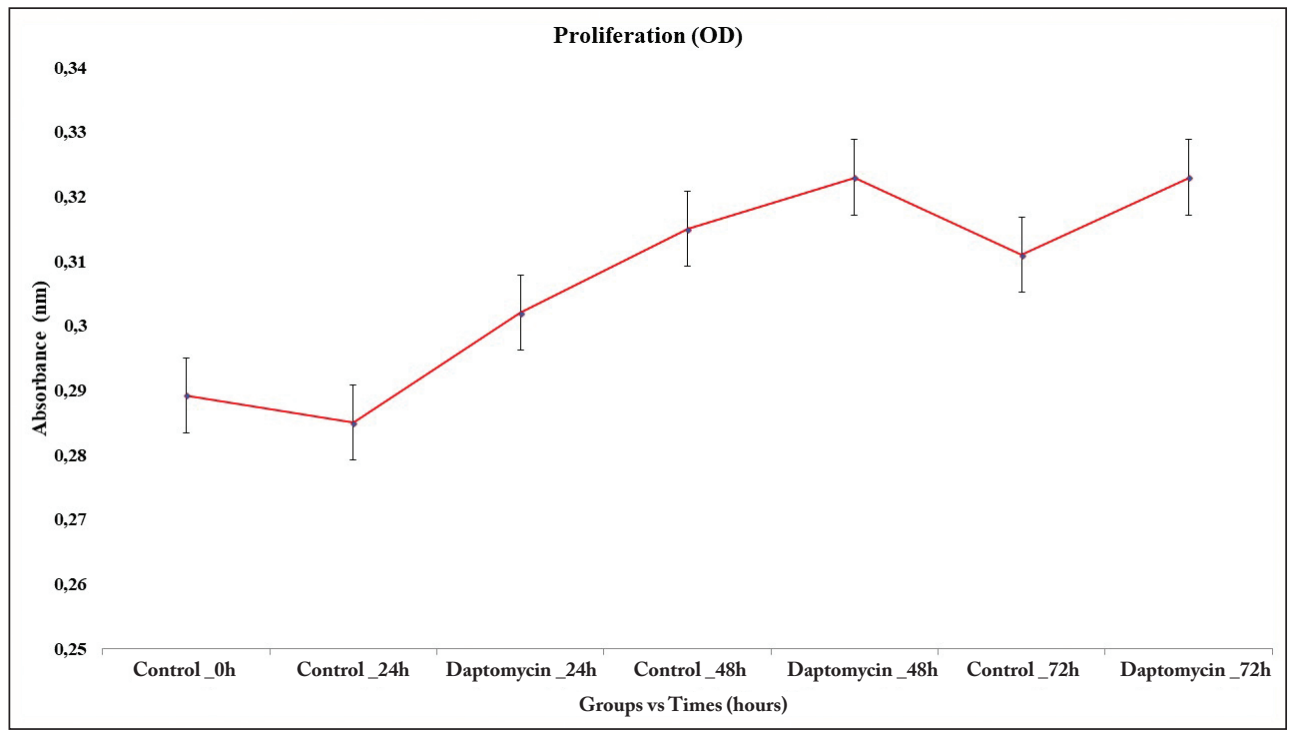

Figure 1: Indication of the time-dependent change in the proliferation as absorbance in the human intact primary cell cultures treated with DAP compared to the non-administered control group. 

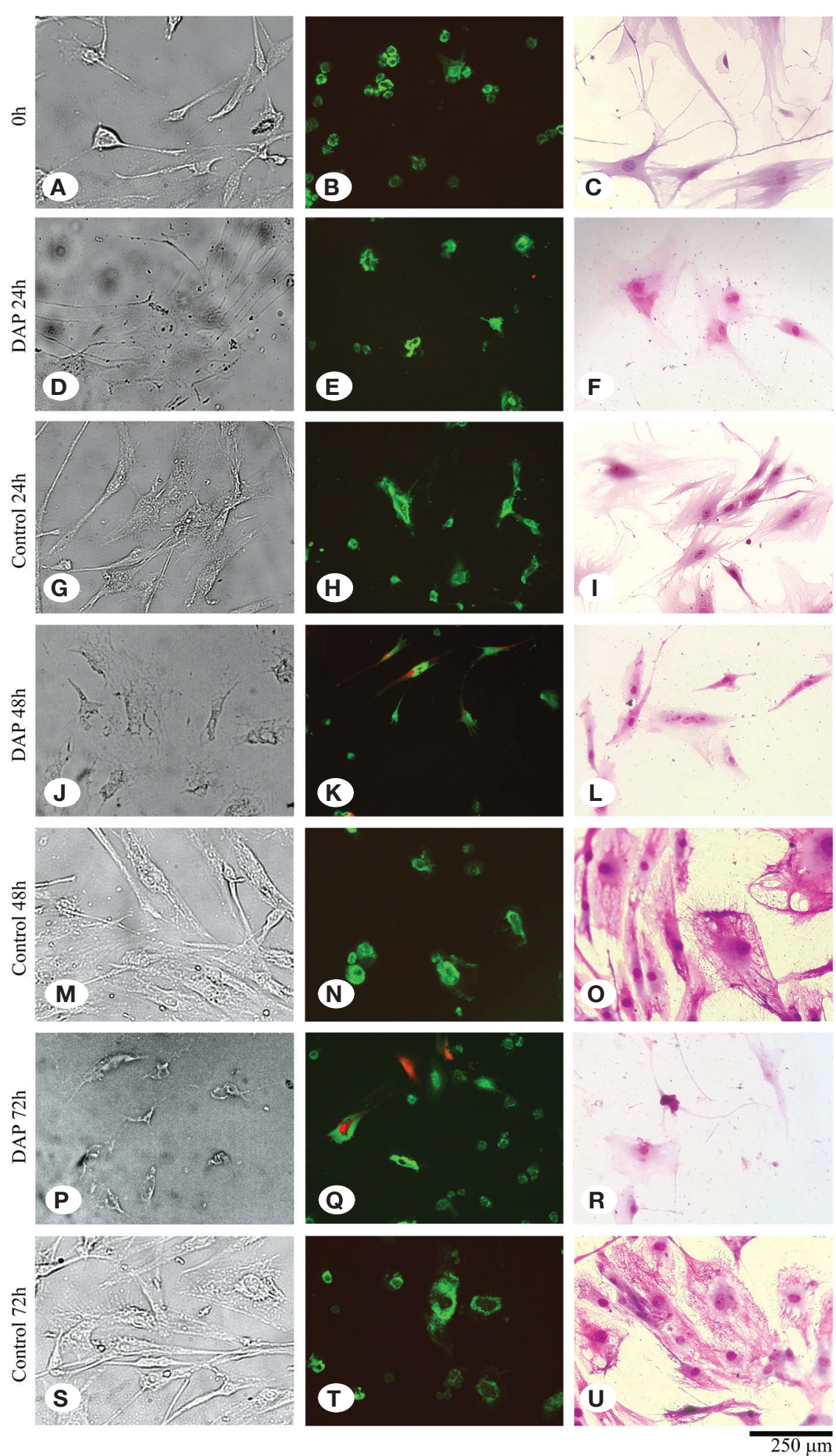

Figure 2: It is seen that the cells are viable, healthy, and adhere to the floor in the non-DAP-administered cell culture samples at 0 hour (A), 24 hours (G), 48 hours (M), and 72 hours (S) inverted light microscope analyses. However, it is observed that the cell number decreases, and the ECM degrades at 24 hours (D), 48 hours (J), and 72 hours (P). Red dead cells are seen in the DAP-administered samples [24 hours (E), 48 hours (K), and 72 hours (Q)] compared to the non-DAP-administered control group samples [0 hour (B), 24 hours (h), 48 hours (N), and 72 hours (T)] in the fluorescence microscope images. In the images obtained with Giemsa staining, it is observed that the number of cell nuclei decreases and the matrix structure is deteriorated in the DAP-administered samples ["F," "L," and "R" images] compared to the control group samples ["C," "I," "O," and "U" images]. 
$R Q=0.9$, respectively. However, CHAD gene expression was 1.4-fold higher in the control group than the DAP applied group $(p<0.05)$. In contrast to CHAD, COMP gene expression increased 2.3-fold in the control group at 24 hours but decreased by $30 \%$ in DAP applied cultures $(p<0.05)$. In the control group, COMP expression was 3.3-fold higher than that of the DAP applied cultures. Similarly, IL-1 $\beta$ gene expression was 3.9-fold higher in in the control group than cultures treated with DAP. The expression of the MMP-7 gene in the control group decreased by $30 \%$, whereas it was not expressed in cultures in which DAP was applied $(p<0.05)$. While the MMP19 gene expression remained unchanged in the control group at 24 hours, it decreased by $40 \%$ in the DAP-administered cultures and expressed 1.6-fold less than the control group (Figure 3).

The number of live cells increased in both the control group and in the cultures treated with DAP at 48 hours. Although there were more cells in the DAP applied cultures than the control group, after AO/PI staining, it was observed that some of the cells began to die with apoptosis in the DAP applied cultures (Figure 2A-U). Furthermore, although the cells maintained their vitality in this group, their morphology began to change and deteriorate (Figure 2A-U). When gene expressions were examined in 48 hours samples, a 2.5-fold decrease in CHAD, a 2.4-fold decrease in COMP, a 10.6-fold decrease in IL-1 $\beta$, and a 2.5-fold decrease in MMP-7 expression were determined in the DAP applied cultures compared to the control group $(p<0.05)$. There was no significant change in the expression of the MMP-19 gene (Figure 3).
In the 72-hour control group cultures, the cells reached the transient stage due to increased confluency, and it was observed that the number of viable cells was approximately the same as that of the 48 hours cultures in the MTT assay. A similar condition applies to cultures in which DAP is applied (Figure 1). However, in inverted microscopy examinations of AO/PI stained cultures, apoptosis and deterioration in cell morphology were defined in cultures treated with DAP (Figure 2A-U). When gene expressions were examined in 72-hour samples, a 7.4-fold decrease in CHAD, a 3.7-fold decrease in COMP, a 4.7-fold decrease in IL-1 $\beta$, and a 10fold decrease in MMP-7 expression were determined in the DAP applied cultures compared to the control group. MMP-19 gene expression remained unchanged (Figure 3). The proliferation data obtained from the MTT analysis were statistically evaluated, and changes in the number of viable cells was found to be statistically meaningful $(p<0.05)$. The expression of CHAD, COMP, IL-1 $\beta$, and MMP-7 were reported to significantly decrease in the DAP applied group samples, and all these results were found to be statistically significant $\mathrm{p}<0.05)$.

\section{DISCUSSION}

In cases such as septic arthritis, osteomyelitis, and spondylodiscitis, antibiotics can be used in long-term, high, and repeated doses $(7,22,25,38)$. In addition to their side effect profile, antibiotics used in this way may also have adverse effects that cause toxicity, particularly during surgery, to avoid such negativities $(9,10,17,22,25,27,31)$.

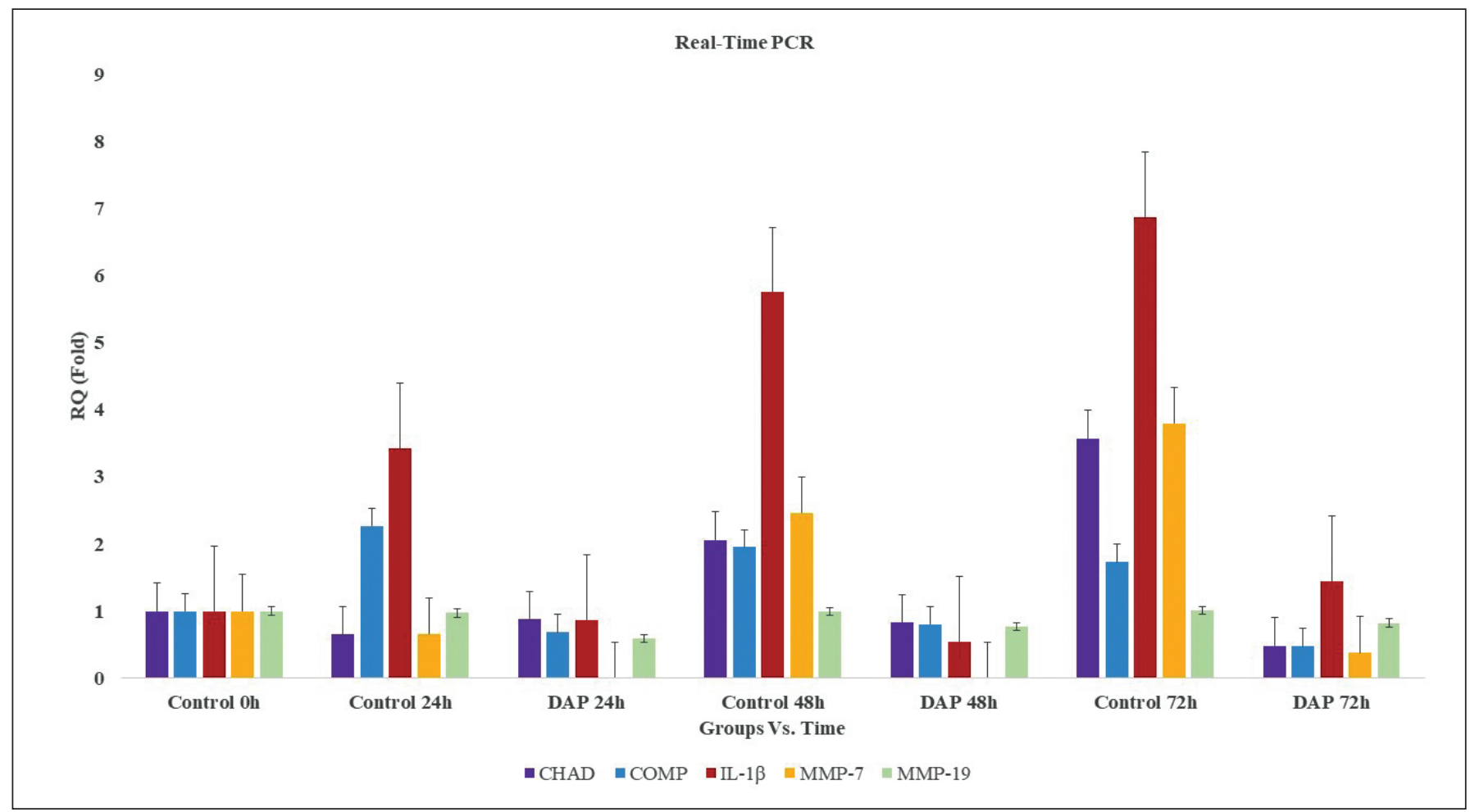

Figure 3: Comparison of the gene expressions of CHAD, COMP, IL-1 $\beta$, MMP-7, MMP-19, and the values of the relative quantity as fold in groups treated with and without DAP. 
The local administration of antibiotics - such as the use of antibiotic-containing cement chains, antibiotic-impregnated absorbable haemostatic sponges, or gels and grafts to prevent intra-operative prophylaxis and/or infection-looks promising in the field of neurosurgery $(10,12,41)$. However, even when used locally, toxic effects were reported in the literature (10). Many studies have revealed the toxic effects of antibiotics on vertebra, bone, and cartilage tissue, and this has put restrictions on surgeons working in the relevant fields (25).

Many drugs taken into the body by any means, whether orally or parenterally, accumulate in the synovial fluid compartment. In addition, studies have reported that DAP accumulates in the synovial fluid following its administration into the body $(1,7,19-21,23-25,42,43)$.

The side effects of DAP have been reported widely in the literature and product monographs and prospectuses $(5,11,28,39,45)$. However, no research has been found in the literature regarding the effect of this glycopeptide agent on the intervertebral disc tissue cells.

This study, which is the first in the literature, aims to evaluate the effect of DAP on proliferation in primary cell cultures isolated from intact human intervertebral disc tissue. The proliferation of cells was evaluated qualitatively and quantitatively. In addition, the value of CHAD-which is one of the NP-specific marker proteins and related to the development of the spinal cord and the dorsal column-was calculated (25). The gene expression levels of COMP (37), IL-1 $\beta(16,37)$, MMP-7, and MMP-19 $(16,37)$ were also analyzed.

Only a few antibiotics, including the glycopeptide group of antibacterial agents and the quinolone group, were evaluated in terms of the chondrotoxicity in the cytotoxic studies $(1,7,10,14,15,19-21,23-25,42,43,44)$.

When reviewing the literature, it is seen that toxicity studies were generally performed with the tissues obtained from animals $(1,7,10,19-21,23-25,42,43)$. However, it has been indicated that the sensitivity of human and animal tissues is different, and therefore the results obtained from studies of animal tissues may not be applicable to human tissues and assuming otherwise may be misleading $(1,7,10,19-21,23-$ 25,42-44).

Other than the cell cultures prepared after the resection of animal tissues, the commercial cell line systems can be used when investigating the cytotoxicity of a drug $(1,7,10,19$ $21,23-25,42,43)$. However, the commercial cell lines contain a single cell type and do not have the complex coordination of cells with their microenvironment and ECM structure. Tests are complicated as a result of the inability of the drug to interact with microstructures, such as the ECM in the cell and its surroundings. Moreover, since the genetic structure of the cells in the cell line has been modified, the cells do not have the genotypic and/or phenotypic characteristics that they have in the human body $(1,7,19-21,23-25,42,43)$.

For these reasons, neither commercial cell lines nor animal tissues were used in this research. To obtain reliable results, the primary cell cultures were prepared from surgically obtained intact human intervertebral disc tissue. The cytotoxicity of DAP to the NP/AF cells and ECM components was tested at the pharmaco-molecular level in these prepared cultures.

Human CHAD has been reported to modulate chondrocyte differentiation by affecting collagen fibrillogenesis. It was been reported that the negative regulatory role of $C H A D$ affects the formation of as table ECM. In addition, thanks to CHAD helps many members of the leucine-rich repeat protein family that is present in articular cartilage to interact with collagen and affect collagen fibrillogenesis $(18,33,46)$.

When examining MTT results, it was observed that cell proliferation continued in both DAP-administered cultures and the control group $(p<0.05)$. We performed our study using primary cultures established from intact AF/NP tissues. An important contribution of our study is that the primary cultures that we established have a heterogeneous structure that contains almost all elements of the tissue from where it originated.

Microscopic examinations at 48 hours and 72 hours revealed morphological deterioration and apoptotic cell death in AO/PI staining in cultures treated with DAP. However, the cells that secured their vitality in these cultures continued to proliferate. The fact that there was no difference between the cultures treated in the MTT assay and the control group is probably due to this. In our primer cultures consisting of heterogeneous cell types, it is likely that some cells may have resisted the effects of DAP. DAP is used in particular to prevent post-operative infections. It is undoubtably important for preventing possible infections. However, apoptosis in the tissue may have a strong negative affect on the natural healing process. In the process of tissue healing, perhaps the most important marker would be the cells that protect their vitality and can form and attach to the ECM. For this reason, it is important that AF/NP cells express genes such as CHAD and COMP, which are important for ECM maintenance and the relation between cells and the ECM.

In our quantitative RT-PCR analyses, the expressions of CHAD and COMP genes were observed to be significantly reduced in DAP-administered cultures compared to the control group $(\mathrm{p}<0.05)$. The deterioration in cell morphology that was observed at 48 hours and 72 hours in cultures treated with DAP may be explained in part by the decrease in the expression of these genes.

IL-1 $\beta$ gene expression was also evaluated to be able to respond in part to the questions whether there is degeneration in the cultured intact AF/NP cells and whether ECM destruction is occurring in these cultures. Increased IL-1 $\beta$ in in vitro conditions is due to ECM degradation observed in patients with inflammation. The fragments resulting from ECM degradation induce IL-1 $\beta$ secretion of AF/NP cells. In cultures treated with DAP, the expression of IL-1 $\beta$ genes was significantly decreased time-dependently $(p<0.05)$. This may be regarded as a sign of protection of the intact form of cells that managed to escape from apoptosis in the cultures. In addition, the expression of MMP-7 and MMP-19 genes, which function in the degradation of COMP protein that allows the binding of the ECM components and cells to the 
extracellular matrix, was evaluated. The expression of genes encoding these proteolytic enzymes was reduced by DAP application. Therefore, it may be suggested that the use of DAP in treatment will not increase inflammation in patients.

These cultures have heterogeneous populations that include all the cell types of the original tissue as well as matrix elements. The fact that the study was performed in primary cultures is an important aspect of our study, as the results we obtained are the closest to those that can be obtained from the original tissue.

\section{CONCLUSION}

In this molecular-based research, it was observed that DAP, particularly when used to treat surgical infections caused by MRSA, did not adversely affect the proliferation of intact human primary intervertebral disc tissue in cell cultures. The drug doses administered were calculated according to the amount intended to reach the tissue via systemic administration, and the DAP doses that were studied in different tissues in the literature. Since our study was not a dose-response study, the applications were performed in a single dose. It may be said that the clinical application of the specified doses is safe in terms of cell viability. However, with the exception of the doses and durations mentioned in the study, the positive and negative effects of DAP administered in increasing doses and over prolonged periods on the viability of the cell population and gene expressions cannot be determined with the results obtained from this study.

\section{- REFERENCES}

1. Akyuva Y, Kaplan N, Yilmaz I, Ozbek H, Sirin DY, Karaarslan N, Guler O, Ates O: Delivering growth factors through a polymeric scaffold to cell cultures containing both nucleus pulposus and annulus fibrosus. Turk Neurosur 2018 (Epub ahead of print)

2. Antony SJ: Combination therapy with daptomycin, vancomycin, and rifampin for recurrent, severebone and prosthetic joint infections involving methicillin-resistant Staphylococcus aureus. Scand J Infect Dis 38: 293-295, 2006

3. Avery LM, Steed ME, Woodruff AE, Hasan M, Rybak MJ: Daptomycin-nonsusceptible vancomycin-intermediatest a phylococcusaureus vertebral osteomyelitis cases complicated by bacteremia treated with high-dosedaptomycin and trimethoprim-sulfamethoxazole. Antimicrob Agents Chemother 56: 5990-5993, 2012

4. Back DA, Bormann N, Calafi A, Zech J, Garbe LA, Müller M, Willy C, Schmidmaier G, Wildemann B: Testing of antibiotic releasing implant coatings to fight bacteria in combatassociated osteomyelitis-an in-vitro study. Int Orthop 40: 1039-1047, 2016

5. Barreau S, Benaboud S, Kernéis S, Moachon L, Blanche P, Groh M, Massias L, Treluyer JM, Poyart C, Raymond J: Staphylococcus aureus osteo-articular infection: Usefulness of the determination of daptomycin serum concentration to explain a treatment failure. Int J Clin Pharmacol Ther 54:923927, 2016

6. Bionda N, Pitteloud JP, Cudic P: Cyclic lipodepsipeptides: A new class of antibacterial agents in the battle against resistant bacteria. Future Med Chem 5: 1311-1330, 2013
7. Burdette SD: Daptomycin for methicillin-resistant Staphylococcus aureus infections of the spine. Spine J 9:e5-8, 2009

8. Denetclaw TH, Suehiro I, Wang PK, Tolliver GL: Successful treatment of ventriculostomy-associated meningitis caused by multidrug resistant coagulase-negative Staphylococcus epidermidis using low-volume intrathecal daptomycin and loading strategy. Ann Pharmacother 48: 1376-1379, 2014

9. Dimovska-Gavrilovska A, Chaparoski A, Gavrilovski A, Milenkovikj Z: The importance of perioperative prophylaxis with cefuroxime or ceftriaxone in the surgical site infections prevention after cranial and spinal neurosurgical procedures. Pril (Makedon Akad Nauk Umet Odd Med Nauki) 38:85-97, 2017

10. Dogan M, Isyar M, Yilmaz I, Bilir B, Sirin DY, Cakmak S, Mahirogullari M: Are the leading drugs against Staphylococcus aureus really toxic to cartilage? J Infect Public Health 9:251258, 2016

11. Durante-Mangoni E, Andini R, Parrella A, Mattucci I, Cavezza G, Senese A, Trojaniello C, Caprioli R, Diana MV, Utili R: Safety of treatment with high-dose daptomycin in 102 patients with infective endocarditis. Int J Antimicrob Agents 48:61-68, 2016

12. El-Husseiny $M$, Patel $S$, MacFarlane RJ, Haddad FS: Biodegradable antibiotic delivery system. J Bone Joint Surg $\mathrm{Br}$ 93: 151-157, 2011

13. Gonzales-Ruiz A, Gargalianos-Kakolyris P, Timerman A, Sarma J, José González Ramallo V, Bouylout K, Trostmann U, Pathan R, Hamed K: Daptomycin in the clinical setting: 8-year experience with Gram-positive bacterial infections from the EU-CORE (SM) Registry. Adv Ther 32: 496-509, 2015

14. Goto K, Imaoka M, Goto M, Kikuchi I, Suzuki T, Jindo T, Takasaki W: Effect of body-weight loading onto the articular cartilage on the occurrence of quinolone-induced chondrotoxicity in juvenile rats. Toxicol Lett 216: 124-129, 2013

15. Goto K, Yabe K, Suzuki T, Takasuna K, Jindo T, Manabe S: Gene expression profiles in the articular cartilage of juvenile rats receiving the quinolone antibacterial agent ofloxacin. Toxicology 249: 204-213, 2008

16. Gruber HE, Hoelscher GL, Ingram JA, Hanley EN: Genomewide analysis of pain-, nerve- and neurotrophin-related gene expression in the degenerating human annulus. Molecular Pain 8:63, 2012

17. Haimoto S, Schär RT, Nishimura Y, Hara M, Wakabayashi $\mathrm{T}$, Ginsberg $\mathrm{HJ}$ : Reduction in surgical site infection with suprafascial intrawound application of vancomycin powder in instrumented posterior spinal fusion: A retrospective casecontrol study. J Neurosurg Spine 4:1-6, 2018

18. Heppner JM, Zaucke F, Clarke LA: Extracellular matrix disruption is an early event in the pathogenesis of skeletal disease in mucopolysaccharidosis I. Mol Genet Metab 114: 146-155, 2015

19. Kaplan N, Karaarslan N, Yilmaz I, Sirin DY, Akgun FS, Caliskan T, Simsek AT, Ozbek H: Are the intervertebral disc tissue cells damaged when attempting to prevent thrombus formation with dabigatran which is amongst the new oral anticoagulants? Turk Neurosurg 2018 (Epub ahead of print) 
20. Karaarslan N, Batmaz AG, Yilmaz I, Ozbek H, Caliskan T, Sirin DY, Kaplan N, Oznam K, Ates O: Effect of naproxen on proliferation and differentiation of primary cell cultures isolated from human cartilage tissue. Exp Ther Med 16(3):1647-1654, 2018

21. Karaarslan N, Yilmaz I, Akgun FS, Caliskan T, Simsek AT, Kaplan N, Kaya YE, Sirin DY, Ozbek H, Ates O: Which pharmacological agents may be used to establish healthy, proliferating human primer nucleus pulposus/annulus fibrosus cell cultures? Systematic evaluation of our experience in the light of literature. Merit Res J Med Med Sci 6: 100-110, 2018

22. Karaarslan N, Yilmaz I, Ozbek H, Oznam K, Ates O, Erdem I: Is implant washing and wound irrigation with rifampicin effective for preventing surgical site infections in lumbar instrumentation? Turk Neurosurg 28(6):904-909, 2018

23. Karaarslan N, Yilmaz I, Ozbek H, Sirin Yasar D, Kaplan N, Akyuva Y, Gonultas A, Ates O: Are specific gene expressions of extracellular matrix and nucleus pulposus affected by primary cell cultures prepared from intact or degenerative intervertebral disc tissues? Turk Neurosurg 2018 (Epub ahead of print)

24. Karaarslan N, Yilmaz I, Sirin DY, Ozbek H, Kaplan N, Kaya YE, Akyuva Y, Gurbuz MS, Oznam K, Ates O: Does pregabalin used in the treatment of neuropathic pain damage intervertebral disc tissue? Exp Ther Med 16: 1259-1265, 2018

25. Karaarslan N, Yilmaz I, Sirin DY, Ozbek H, Kaya YE, Akyuva Y, Kaplan N, Dogan M, Gumustas SA, Ates O, Erdem I: Does transcription factor, induced by daptomycin and vancomycin, affect HIF-1a, Chondroadherin, and COL2A1? Ann Med Res 28: 1-8, 2018

26. Kazory A, Dibadj K, Weiner ID: Rhabdomyolysis and acute renal failure in a patient treated with daptomycin. J Antimicrob Chemother 57: 578-579, 2006

27. Lee GI, Bak KH, Chun HJ, Choi KS: Effect of using local intrawound vancomycin powder in addition to intravenous antibiotics in posterior lumbar surgery: Midterm result in a single-center study. Korean J Spine 13: 47-52, 2016

28. Leuthauser A, Paul A: Hip pain and fever: When it's not a septic joint, what's next? Pediatr Emerg Care 31: 42-43, 2015

29. Li C, Zhang X, Huang X, Wang X, Liao G, Chen Z: Preparation and characterization of flexible nanoliposomes loaded with daptomycin, a novel antibiotic, for topical skin therapy. Int $J$ Nanomedicine 8:1285-1292, 2013

30. Liu B, Karttunen M: Lipopeptide daptomycin: Interactions with bacterial and phospholipid membranes, stability of membrane aggregates and micellation in solution. Biochim Biophys Acta 2018 (Epub ahead of print)

31. Lourtet-Hascoët J, Félicé MP, Bicart-See A, Bouige A, Giordano G, Bonnet E: Species and antimicrobial susceptibility testing of coagulase-negative staphylococci in periprosthetic joint infections. Epidemiol Infect 146(14):1771-1776, 2018

32. Ma Z, Lasek-Nesselquist E, Lu J, Schneider R, Shah R, Oliva G, Pata J, McDonough K, Pai MP, Rose WE, Sakoulas G, Malik $M$ : Characterization of genetic changes associated with daptomycin nonsusceptibility in Staphylococcus aureus. PLoS One 2018 13:e0198366, 2018

33. Mansson B, Wenglén $C$, Mörgelin $M$, Saxne T, Heinegård D: Association of chondroadherin with collagen type II. J Biol Chem 276: 32883-32888, 2001
34. Marty FM, Yeh WW, Wennersten CB, Venkataraman L, Albano E, Alyea EP, Gold HS, Baden LR, Pillai SK: Emergence of a clinicaldaptomycin-resistant Staphylococcus aureusisolate during treatment of methicillin-resistant Staphylococcus aureusbacteremia and osteomyelitis. J Clin Microbiol 44: 595597,2006

35. McConnell HL, Perris ET, Lowry C, Lodise T, Patel N: Effect of concomitant 3-hydroxy-3-methyl-glutaryl-coa reductase inhibitor therapy on creatine phosphokinase levels and mortality among patients receiving daptomycin: Retrospective cohort study. Infect Dis Ther 3: 225-233, 2014

36. Mercuro NJ, Davis SL, Zervos MJ, Herc ES: Combatting resistant enterococcal infections: A pharmacotherapy review. Expert Opin Pharmacother 19: 979-992, 2018

37. Molinos M, Almeida CR, Caldeira J, Cunha C, Gonçalves RM, Barbosa MA: Inflammation in intervertebral disc degeneration and regeneration. J R Soc Interface 12: 20141191, 2015

38. Parlato C, di Nuzzo G, Luongo M, Esposito S, Moraci A: Daptomycin in treatment of Methicillin-resistant Staphylococcus aureus diskitis. Neurol Sci 32: 747-748, 2011

39. Pertel PE, Bernardo P, Fogarty C, Matthews P, Northland R, Benvenuto M, Thorne GM, Luperchio SA, Arbeit RD, Alder J: Effects of prior effective therapy on the efficacy of daptomycin and ceftriaxone for the treatment of community-acquired pneumonia. Clin Infect Dis 46:1142-1151, 2008

40. Shiels SM, Tennent DJ, Wenke JC: Topical rifampin powder for orthopaedic trauma part i: Rifampin powder reduces recalcitrant infection in a delayed treatment musculoskeletal trauma model. J Orthop Res 2018 (Epub ahead of print)

41. Shuhendler AJ, Pu K, Cui L, Uetrecht JP, Rao J: Real-time imaging of oxidative and nitrosative stress in the liver of live animals for drug toxicity testing. Nat Biotechnol 32:373- 38, 2014

42. Sirin DY, Kaplan N, Yilmaz I, Karaarslan N, Ozbek H, Akyuva Y, Kaya YE, Oznam K, Akkaya N, Guler O, Akkaya S, Mahirogullari $M$ : The association between different molecular weights of hyaluronic acid and CHAD, HIF-1a, COL2A1 expression in chondrocyte cultures. Exp Ther Med 15: 4205-4212, 2018

43. Sirin DY, Karaarslan N: Evaluation of the effects of pregabalin on chondrocyte proliferation and CHAD, HIF-1a, and COL2A1 gene expression. Arch Med Sci 14(6):1340-1347, 2018

44. Stueber T, Karsten J, Stoetzer C, Lefter A: Differantial cytotoxic properties of drugs used for intra-articular injection on human chondrocytes: An experimental in-vitro study. Eur J Anaesthesiol 31: 640-645, 2014

45. Suleyman G, Kenney R, Zervos MJ, Weinmann A: Safety and efficacy of outpatient parenteral antibiotic therapy in an academic infectious disease clinic. J Clin Pharm Ther 42:3943, 2017

46. Tillgren V, Ho JC, Önnerfjord P, Kalamajski S: The novel small leucine-rich protein chondroadherin-like (CHADL) is expressed in cartilage and modulates chondrocyte differentiation. J Biol Chem 290: 918-925, 2015

47. Tótoli EG, Garg S, Salgado HR: Daptomycin: Physicochemical, analytical, and pharmacological properties. Ther Drug Monit 37: 699-710, 2015 